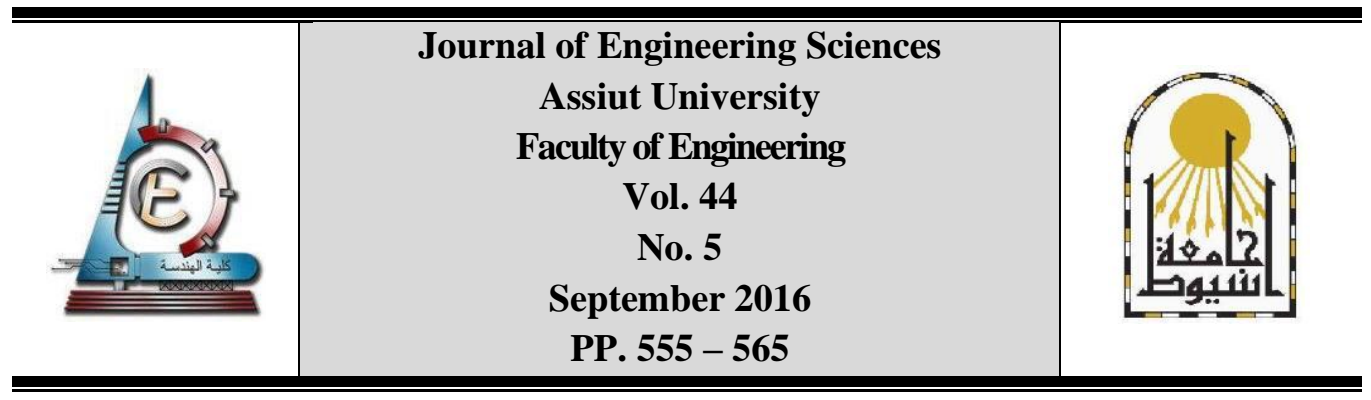

\title{
DEVELOPMENT OF DYNAMIC MODEL FOR VIBRATION CONTROL OF FLEXIBLE BEAM
}

\author{
Mark Adel, Khalil Ibrahim, Abdel-Rassoul Gad, Abo El-Makarem Khalil \\ Department of Mechanical Eng., Faculty of Engineering, Assiut University, Assiut, Egypt \\ Received 30 May 2016; Accepted 29 June 2016
}

\begin{abstract}
The present study aims at developing a new dynamic model for vibration control of a composite carbon cantilever beam. The finite element method (FEM) is used to derive the introduced model. Modal analysis is performed on the cantilever beam using ANSYS software package and results were compared with similar published work using ABAQUS software package to validate the results obtained from ANSYS. The theory behind the extraction of flexible beam model from the finite element model is introduced. The eigenvalues and eigenvectors resulting from this analysis are integrated into MATLAB, which is used to derive the state space model of the system. Through MATLAB/ SIMULINK tools a PID controller was designed and controlled system performance under different system inputs is studied to test the efficiency of the controller. The results show similar responses and similar error percentage signals to various step input angles. In addition, the system shows a good performance to sine wave input signal despite the presence of a minor lag.
\end{abstract}

Keywords: Dynamic model, Finite Element, Modal Analysis, ANSYS, MATLAB

\section{Introduction}

Beam structures have wide applications in many engineering fields such as aeronautic and astronautic engineering, mechanical engineering, and civil engineering. Vibration of beams causes a loss of system stability and eventually leads to system failure. If the flexibility of the structures is large, nonlinear vibrations with large amplitudes will continually occur for a long time under the external forces, which will inevitably influence the structure normal work and even result in the structural fatigue damage [1]. Therefore the idea of suppressing/attenuating structural vibrations is of a great importance for enhancing safety and improving system performance. So far, the problems of structural vibration have attracted the attention of numerous researchers' attention. The proposed techniques to minimize the structural vibrations, in general, consist of two main categories; passive control systems and active control systems. Passive systems add damping to the structure or isolate it from the source of environmental excitation, thus reduce its vibration. These systems have

Corresponding author.

Email address: ben.adel2010@gmail.com 
been widely used because of their simplicity, reliability and low cost, however, their control capacity is limited. In the actively controlled system, control forces are generated using an external energy source and applied to the structure through actuators according to a prescribed control algorithm. Active systems have the advantage of strong control capacity and can be designed to influence a number of vibration modes [2].

The main step towards a valid study on the effect of control system on flexible beam response is to obtain the beam model; hence beam vibration analysis must be performed first. Several studies have been carried out to investigate the vibrations of cantilever beam under active control systems (e.g. Xu et al. [3], H. Nasser et al. [4] and Khot et al. [5]).

The objective of this work is to develop a new dynamic model for the vibration control of a cantilever beam using the finite element analysis. Since real systems are usually quite complicated when viewed in detail, an exact analysis of any system is quite complicated. Thus, simplifying assumptions must be made to reduce the system to an idealized version whose behavior approximates that of the real system. The process by which a physical system is simplified to obtain a mathematically tractable situation is called modeling [6]. The resulting simplified version of the real system is called the model of the system.

In the current study the dynamic model of a composite carbon cantilever beam is derived from the results of a 2-D modal analysis of the beam FEM model performed using ANSYS software. The extraction of system model and the study of system response to PID controller are carried out in a MATLAB based environment.

This paper is organized as follows. In section II beam properties are presented. The finite element analysis of the studied cantilever beam is discussed in section III while the extraction of system model is described in section IV. In section V, design of the controller and simulation of system response are presented, followed by results discussion in section VI.

\section{Composite carbon cantilever beam}

For the present analysis, a composite carbon cantilever beam is studied as shown in Fig. 1. The beam dimensions are similar to those used by H. Nasser et al. [4].

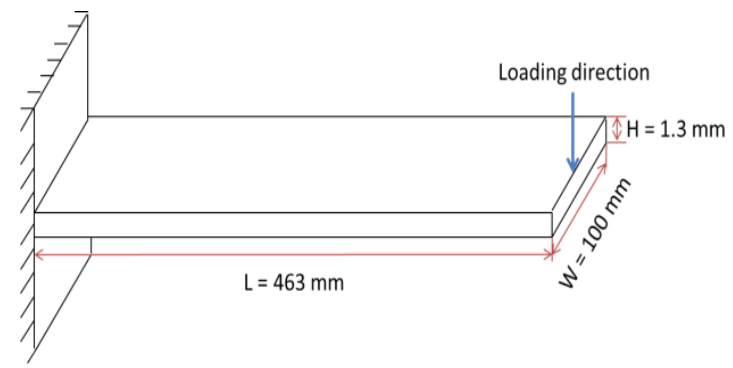

Fig. 1. Composite carbon beam geometry

Table 1.

Mechanical properties of composite carbon cantilever beam

\begin{tabular}{|c|c|}
\hline Young's Modulus of Composite Carbon & $\mathrm{E}=41.5 \mathrm{GPa}$ \\
\hline Poisson's Ration of Composite Carbon & $v=0.042$ \\
\hline Density of Composite Carbon & $\rho=1480 \mathrm{~kg} / \mathrm{m}^{3}$ \\
\hline Area Moment of Inertia & $\mathrm{I}=1.83 \times 10^{-11} \mathrm{~m}^{4}$ \\
\hline
\end{tabular}




\section{Finite element analysis}

\subsection{Software validation}

First, a validation of the software result was performed through a static analysis of the beam when subjected to tip load of $10 \mathrm{~N}$ and comparing the maximum deflection with that of the mathematical value. The result is shown in Fig. 2. From the above figure, the maximum deflection (at tip) is $0.4356 \mathrm{~m}$ as per the mathematical value.

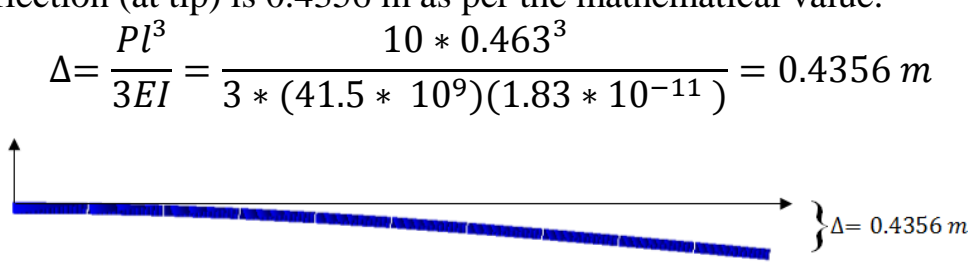

Fig. 2. Static analysis of beam when subjected to tip loading of $10 \mathrm{~N}$

\subsection{FE Analysis of beam}

Free vibration modal analysis is performed on the beam in which BEAM3 element is used for the analysis. The Block Lanczos method is used to find the eigenvalues and the eigenvectors normalized with respect to the beam mass. Eigenvectors corresponding to the Y-component degrees of freedom are used in the vibration analysis. The beam was divided 10 elements and 10 modes were extracted. The shapes of the first 3 modes are shown in Fig. 3.
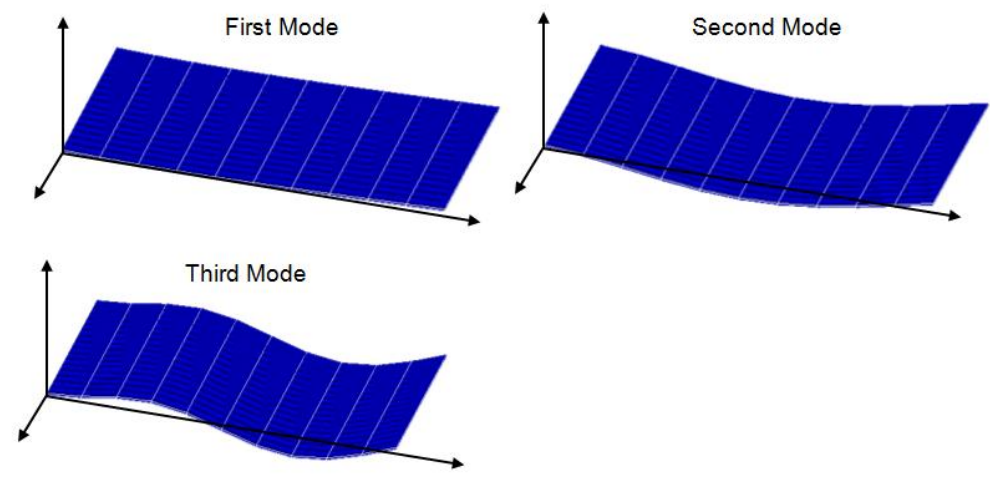

Fig. 3. Modal analysis of composite carbon beam

The results of the first 3 modes extracted from ANSYS were compared with the first 3 modes extracted from ABAQUS by H. Nasser et al. [4] as shown in Table 2.

Table 2.

Modal analysis results obtained from ANSYS

\begin{tabular}{|c|c|c|}
\hline Mode No. & Natural frequencies $(\mathrm{Hz})$ - ANSYS & Natural frequencies $(\mathrm{Hz})$ - ABAQUS \\
\hline 1 & 5.1688 & 5.1715 \\
\hline 2 & 32.3923 & 32.486 \\
\hline 3 & 90.721 & 91.399 \\
\hline
\end{tabular}

Now the analysis is performed on aluminum beam and the result compared with composite carbon beam as shown in Fig. 4. 


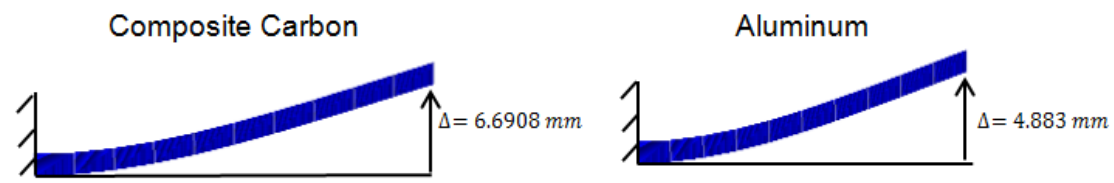

Fig. 4. Modal analysis showing first mode of composite carbon and aluminum beams

The above results could be summarised in Table 3 .

Table 3.

Modal analysis performed on composite carbon and aluminum cantilever beams

\begin{tabular}{|c|c|c|c|c|c|}
\hline Material & $\begin{array}{c}\text { Young's } \\
\text { Modulus } \\
(\mathrm{GPa})\end{array}$ & $\begin{array}{c}\text { Poisson's } \\
\text { Ratio }\end{array}$ & $\begin{array}{c}\text { Density }(\mathrm{kg} / \\
\left.\mathrm{m}^{3}\right)\end{array}$ & $\begin{array}{c}\text { First Mode } \\
\text { Frequency } \\
(\mathbf{H z})\end{array}$ & $\begin{array}{c}\text { Tip deflection } \\
(\mathbf{m m})\end{array}$ \\
\hline $\begin{array}{c}\text { Composite } \\
\text { Carbon }\end{array}$ & 41.5 & 0.042 & 1490 & $\mathbf{5 . 1 6 8}$ & $\mathbf{6 . 6 9 0 8}$ \\
\hline Aluminum & 70 & 0.35 & 2800 & $\mathbf{4 . 8 9 7}$ & $\mathbf{4 . 8 8 3}$ \\
\hline
\end{tabular}

It is clear from Table 3 that composite carbon shows a higher natural frequency and a higher tip deflection compared with the aluminum beam, which indicates a higher flexibility.

\section{Beam model}

\subsection{State space model}

The construction of mathematical model analytically for complicated real life dynamic structures is very difficult and time consuming. This itself may become constraint in implementing active vibration control strategies for real life application. Therefore in present study extraction of the mathematical model of a dynamic system from the results of modal analysis of its finite model done in ANSYS is illustrated.

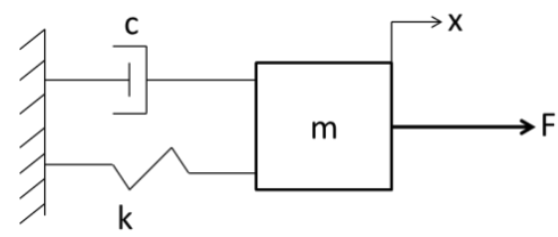

Fig. 5. Mass Spring Damper System

\subsubsection{Modal analysis}

The equations of motion of a multi degree of freedom system under external forces (an example is shown in Fig. 5) are given by:

$$
[m] \ddot{x}+[c] \dot{x}+[k] x=F .
$$

Since $[\mathrm{m}],[\mathrm{c}]$ and $[\mathrm{k}]$ are non-diagonal matrices, the above expression leads to $n$ coupled second order differential equations. To uncouple these equations, first the eigenvalue problem is solved for equation (1) and the eigenvectors are obtained as $x_{(1)}, x_{(2)}$, $\ldots x_{(n)}$. The modal matrix for the system is defined as:

$$
\left[x_{n}\right]=\left[x_{(1)} x_{(2)} \ldots x_{(n)}\right] .
$$

For a multi degree of freedom system with the assumption of proportional damping, the solution of equation 6 can be expressed as a linear combination of the normal modes as: 


$$
x(t)=\left[x_{n}\right] x_{p}(t),
$$

where $x_{p}(t)$ is known as the displacement in principal coordinates. If the normal modes are normalized with respect to mass, the equations of motion in the principal coordinates can be written in the form of:

$$
\ddot{x}_{p i}+2 \xi_{i} \omega_{i} \dot{x}_{p i}+\omega_{i}^{2} x_{p i}(t)=F_{p i}(t),
$$

where $i=1,2, \ldots, n$ and

$$
F_{p}(t)=\left[x_{n}\right]^{T} F(t) .
$$

$F_{p}(t)$ is the vector of forces in principal co-ordinates. Thus, a set of $n$ uncoupled differential equations of the second order is obtained from the set of $n$ coupled differential equations of the second order. These $n$ uncoupled differential equations of the second order are converted into the state space form as $2 n$ differential equations of the first order. A general algorithm for analyzing a vibrating structure using ANSYS and MATLAB [8] is summarized in the following section.

\subsubsection{General theory of model extraction}

The state-space model of the system may be constructed by using eigenvalues and eigenvectors normalized with respect to mass. The state space representation model is described by the following equation [10]:

$$
\begin{gathered}
\dot{x}=A x+B u \\
y=C x+D u
\end{gathered}
$$

where, $x$ is column vector representing the state of the system, $y$ is output matrix, $u$ is input matrix, $A$ is system matrix, $B$ is input matrix, $C$ is output matrix and $D$ is direct transmission matrix. The matrices $A, B, C$ and $D$ of equations (6) and (7) for a system with $n$ modes can be written as follow [9]:

$$
\begin{aligned}
A & =\left[\begin{array}{ccccc}
0 & 1 & \ldots & \ldots & \ldots \\
-\omega_{1}^{2} & -2 \xi_{1} \omega_{1} & \ldots & \ldots & \ldots \\
\ldots & \ldots & \ldots & \ldots & \ldots \\
\ldots & \ldots & \ldots & \ldots & \ldots \\
\ldots & \ldots & \ldots & -\omega_{n}{ }^{2} & -2 \xi_{n} \omega_{n}
\end{array}\right], \\
B & =\left[\begin{array}{c}
0 \\
F_{p_{1}} \\
0 \\
F_{p_{2}} \\
\ldots \\
F_{p_{n}}
\end{array}\right]
\end{aligned}
$$

where $F_{p}=\left[\begin{array}{llll}F_{p 1} & F_{p 2} \ldots F_{p n}\end{array}\right]^{T}$ is the force vector in principal co-ordinates. Value of $C$ depends upon the output of interest. Since the values of displacement of the nodes are desired, $C$ is given by 


$$
C=\left[\begin{array}{ccccc}
x_{n 11} & 0 & x_{n 12} & 0 & \ldots \\
0 & 0 & 0 & 0 & \ldots \\
x_{n 21} & 0 & x_{n 22} & 0 & \ldots \\
\ldots & \ldots & \ldots & \ldots & \ldots
\end{array}\right]
$$

where $x_{n 11}, x_{n 12}, \ldots$ are the elements of $x_{n}$, the modal matrix normalized with respect to mass. $D$ is the direct transmission matrix. Here,

$$
D=[0]
$$

In this way the system matrices $A, B, C$ and $D$ may be written by inspection once the eigenvalues and eigenvectors are known. By importing eigenvalues and eigenvectors in MATLAB, matrices $A, B, C$ and $D$ can be constructed.

\subsubsection{Model extraction}

The results obtained from ANSYS can be used in MATLAB to obtain a suitable model of the flexible beam for application of a control method. An approach to this is by extracting eigenvalues and eigenvectors obtained from modal analysis in MATLAB to be used for deriving a state space model of the system [5]. The results of the FEM analysis are written to a file with the extension .eig, which is read in MATLAB. As per the below figure, the main interest will be node 2 at the tip (see below Fig. 6) where the maximum deflection occurs.

\section{$\begin{array}{lllllllllll}1 & 3 & 4 & 5 & 6 & 7 & 8 & 9 & 10 & 11 & 2\end{array}$}

Fig. 6. Nodes of the cantilever beam (11 nodes)

The eigenvalues and eigenvectors of the mentioned system are extracted in MATLAB using the code "ext56uy.m". The eigenvector is found to be as follows:

$\left[\begin{array}{c}0 \\ 32.393 \\ 90.721 \\ 177.9 \\ 294.53 \\ 441.22 \\ 619.03 \\ 829.29 \\ 1072.2 \\ 1332.8\end{array}\right]$

Frequency response for the full model for all 10 modes is plotted in Fig. 7.

The state space representation model is described by equations (6) and (7) where the state space matrices A, B, C and D are derived for the full model and are expressed as follows:

\section{Control simulation}

\subsection{Controller design}

Simulation of the virtual prototype has been accomplished by combining MATLAB/Simulink to ANSYS software package. The resulted outputs of the virtual prototype are then feedback to the controller in MATLAB/Simulink for calculation of the next command signal. The physical system is shown in Fig. 8 while the schematic diagram 
in Fig. 9 illustrates the inputs and outputs variables for the virtual prototype. The DC motor is modeled by the following transfer function:

$$
P(s)=\frac{\dot{\theta}(s)}{V(s)}=\frac{K}{(J s+b)(L s+R)+K^{2}} \quad\left[\frac{\mathrm{rad} / \mathrm{sec}}{\mathrm{V}}\right]
$$

The parameters in equation (12) are summarized in Table 4.

$\begin{array}{ccccccccc}c & A=[ \\ & & & & & & & & \\ 1 & 0 & 0 & 0 & 0 & 0 & 0 & 0 & 0 \\ 0 & 0 & 0 & 0 & 0 & 0 & 0 & 0 & 0 \\ 0 & 0 & 1 & 0 & 0 & 0 & 0 & 0 & 0 \\ 0 & -41424 & 0 & 0 & 0 & 0 & 0 & 0 & 0 \\ 0 & 0 & 0 & 0 & 1 & 0 & 0 & 0 & 0 \\ 0 & 0 & 0 & -324919 & 0 & 0 & 0 & 0 & 0 \\ 0 & 0 & 0 & 0 & 0 & 0 & 1 & 0 & 0 \\ 0 & 0 & 0 & 0 & 0 & -1.2 \mathrm{e} 06 & 0 & 0 & 0 \\ 0 & 0 & 0 & 0 & 0 & 0 & 0 & 0 & 1 \\ 0 & 0 & 0 & 0 & 0 & 0 & 0 & -3.4 \mathrm{e} 06 & 0 \\ 0 & 0 & 0 & 0 & 0 & 0 & 0 & 0 & 0 \\ 0 & 0 & 0 & 0 & 0 & 0 & 0 & 0 & 0 \\ 0 & 0 & 0 & 0 & 0 & 0 & 0 & 0 & 0 \\ 0 & 0 & 0 & 0 & 0 & 0 & 0 & 0 & 0 \\ 0 & 0 & 0 & 0 & 0 & 0 & 0 & 0 & 0 \\ 0 & 0 & 0 & 0 & 0 & 0 & 0 & 0 & 0 \\ 0 & 0 & 0 & 0 & 0 & 0 & 0 & 0 & 0 \\ 0 & 0 & 0 & 0 & 0 & 0 & 0 & 0 & 0 \\ 0 & 0 & 0 & 0 & 0 & 0 & 0 & 0 & 0 \\ 0 & 0 & 0 & 0 & 0 & 0 & 0 & 0 & 0\end{array}$

0
0
0
0
0
0
0
0
0
0
0
$-7.6 \mathrm{e} 06$
0
0
0
0
0
0
0
0

$\begin{array}{lll}0 & 0 \\ 0 & 0 & 0 \\ 0 & 0 & 0 \\ 0 & 0 \\ 0 & 0 \\ 0 & 0 \\ 0 & 0 \\ 0 & 0 \\ 0 & 0 \\ 0 & 0 \\ 1 & 0 \\ 0 & 0 \\ 0 & 0 \\ 0 & -1.5 \mathrm{e} 07 \\ 0 & 0 \\ 0 & 0 \\ 0 & 0 \\ 0 & 0 \\ 0 & 0 \\ 0 & 0\end{array}$

$\begin{array}{ll}0 & 0 \\ 0 & 0 \\ 0 & 0 \\ 0 & 0 \\ 0 & 0 \\ 0 & 0 \\ 0 & 0 \\ 0 & 0 \\ 0 & 0 \\ 0 & 0 \\ 0 & 0 \\ 0 & 0 \\ 1 & 0 \\ 0 & 0 \\ 0 & 0 \\ 0 & -2.7 \mathrm{e} 07 \\ 0 & 0 \\ 0 & 0 \\ 0 & 0 \\ 0 & 0\end{array}$

$\begin{array}{lllll}0 & 0 & 0 & 0 & 0 \\ 0 & 0 & 0 & 0 & 0 \\ 0 & 0 & 0 & 0 & 0 \\ 0 & 0 & 0 & 0 & 0 \\ 0 & 0 & 0 & 0 & 0 \\ 0 & 0 & 0 & 0 & 0 \\ 0 & 0 & 0 & 0 & 0 \\ 0 & 0 & 0 & 0 & 0 \\ 0 & 0 & 0 & 0 & 0 \\ 0 & 0 & 0 & 0 & 0 \\ 0 & 0 & 0 & 0 & 0 \\ 0 & 0 & 0 & 0 & 0 \\ 0 & 0 & 0 & 0 & 0 \\ 0 & 0 & 0 & 0 & 0 \\ 1 & 0 & 0 & 0 & 0 \\ 0 & 0 & 0 & 0 & 0 \\ 0 & 0 & 1 & 0 & 0 \\ 0 & -4.5 \mathrm{e} 07 & 0 & 0 & 0 \\ 0 & 0 & 0 & 0 & 1 \\ 0 & 0 & 0 & -7 \mathrm{e} 07 & 0 \\ & & & & ]\end{array}$
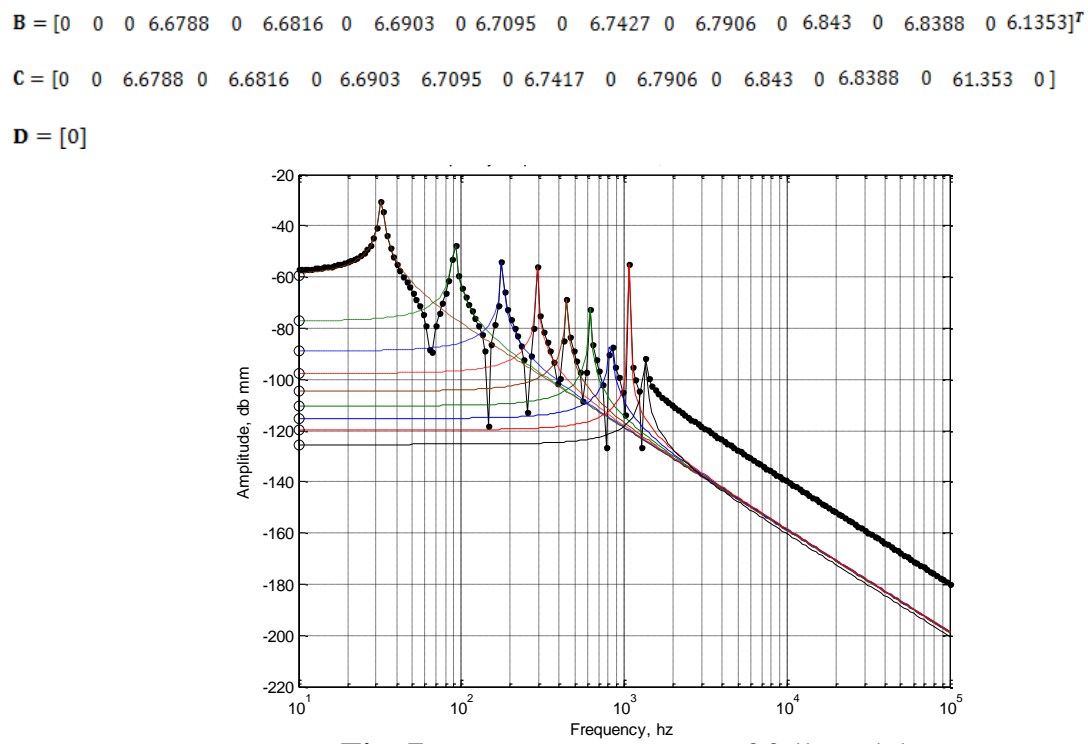

Fig. 7. Frequency response of full model

Table 4.

Parameters of DC Motor

\begin{tabular}{|c|c|c|c|}
\hline Parameter & Description & Value & Unit \\
\hline $\mathrm{J}$ & Moment of inertia of the motor & 0.01 & $\mathrm{Kg} / \mathrm{m}^{2}$ \\
\hline $\mathrm{b}$ & Motor viscous friction constant & 0.1 & $\mathrm{~N} . \mathrm{m} . \mathrm{s}$ \\
\hline \multirow{2}{*}{$\mathrm{K}$} & Electromotive force constant & $36.5 \times 10^{-3}$ & $\mathrm{~V} / \mathrm{rad} / \mathrm{sec}$ \\
\cline { 2 - 4 } & Motor torque constant & $36.5 \times 10^{-3}$ & $\mathrm{~N} . \mathrm{m} / \mathrm{Amp}$ \\
\hline $\mathrm{R}$ & Electric resistance & 2.96 & $\mathrm{Ohm}$ \\
\hline $\mathrm{L}$ & Electric inductance & 2.51 & $\mathrm{H}$ \\
\hline
\end{tabular}


The required end position angle was found to be approximately $20^{\circ}$ as deduced from the tip deflection by FE analysis of the beam. For the current study PID controller is designed using the Simulink Design Optimization (SDO) tool in MATLAB as shown in Fig. 10. This tool will be used to automatically tune controller parameters to meet time-domain requirements. The optimization of any design parameter is carried out by expressing it as a Simulink signal and connecting this signal to the Signal Constraint block provided by SDO. The Signal Constraint block can constrain the signal by either graphically shaping the desired response or specifying a reference signal trajectory as shown in Fig. 8, then, it adjusts the values of chosen model parameters to satisfy the constraints. The signal constraint block GUI is updated during optimization so that the optimization progress can be displayed [7]. Optimization iterations are performed on varying ranges of $K_{p}, K_{i}, K_{d}$ and $N$ (filter coefficient) parameters. The system response to step input based on optimized parameters is simulated assuming negligible natural damping.

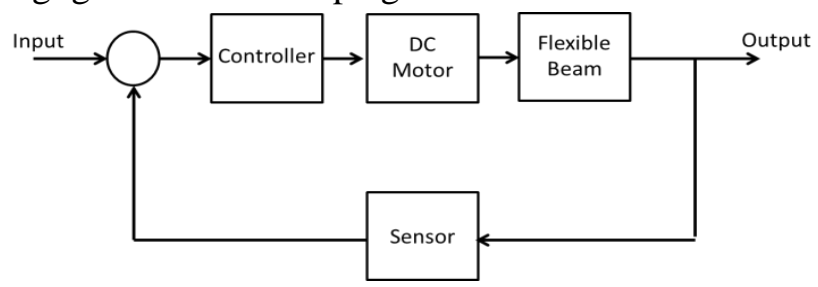

Fig. 8. Block diagram of physical system

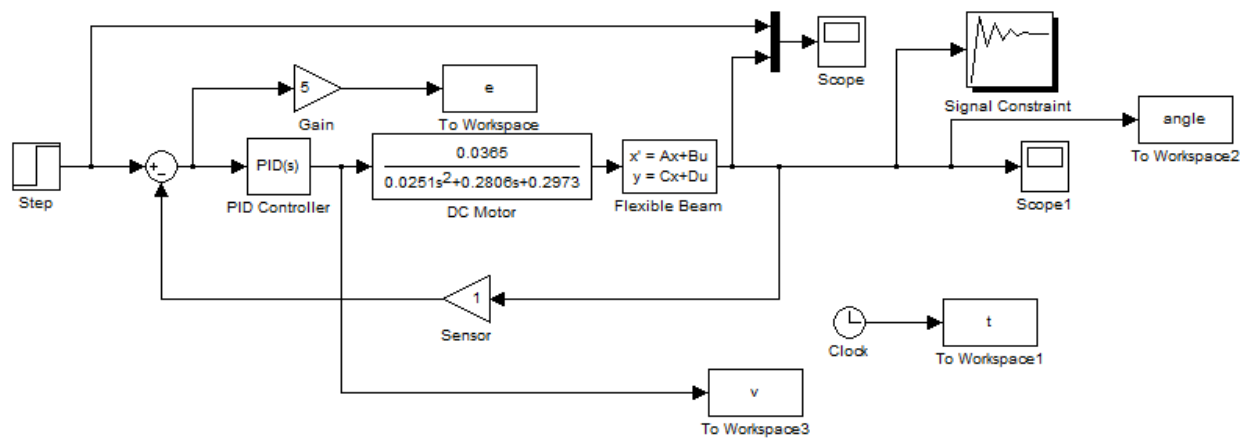

Fig. 9. Simulation block diagram of vibration control system

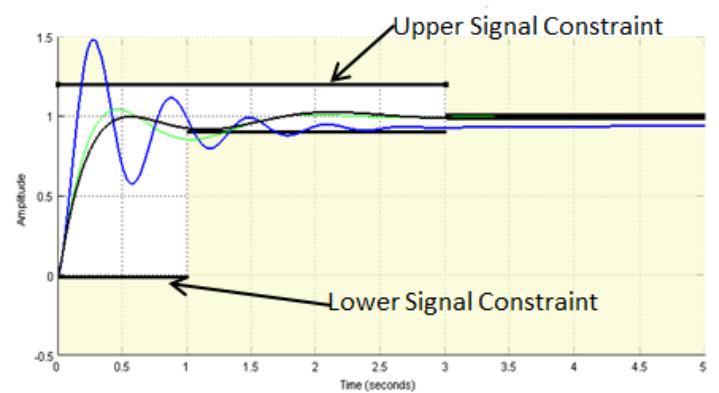

Fig. 10. System design optimization

\section{Results and discussion}

To test the capability of the developed control model, a step input is applied to the beam. From the signal constraint optimization, the PID controller parameters were found to be as follows:

$$
K_{p}=3000, K_{i}=10000, K_{d}=50 \text { and } N=3044 .
$$

The system response to a step input of $20^{\circ}$ is simulated and plotted in Fig. 11. 


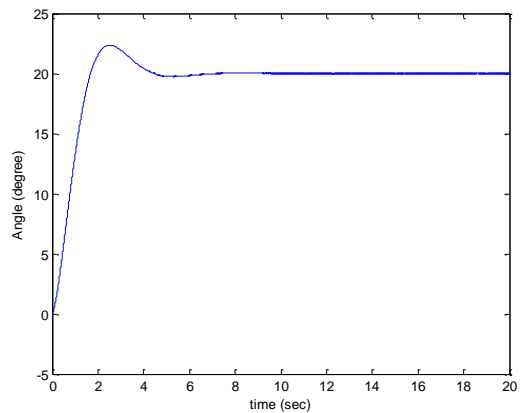

Fig. 11. System response of controlled model to a step input of $20 \mathrm{o}$

The variations of the system response and error percentage signals with time are plotted in Figs. 12, 13, 14 and 15 for step inputs of $20^{\circ}, 15^{\circ}, 10^{\circ}$ and $5^{\circ}$ respectively.
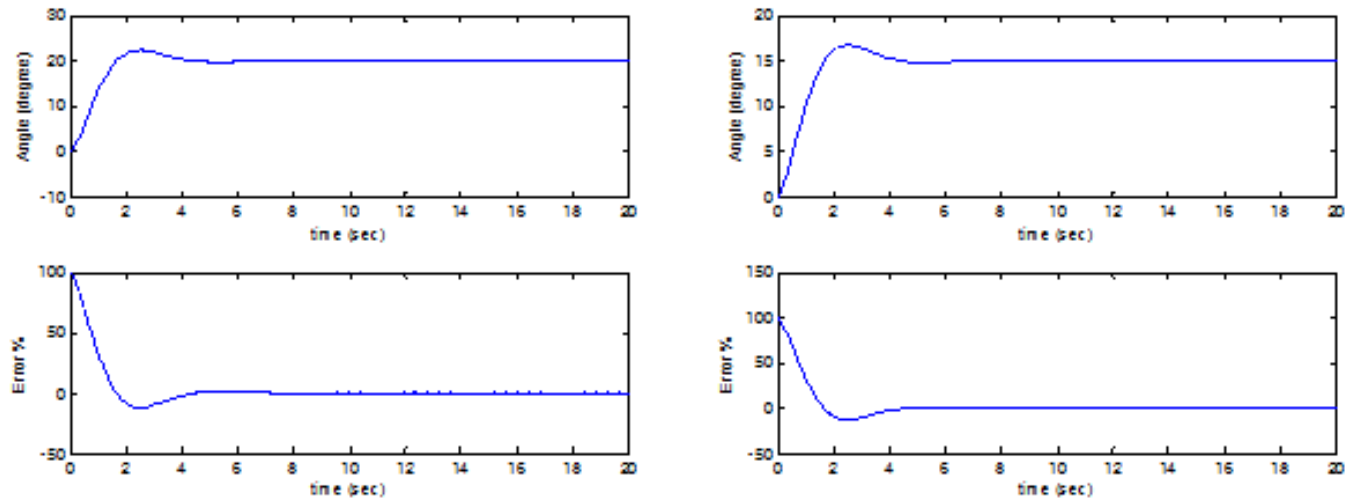

Fig. 12. Variations of the controlled system response and error signal a step input of 200

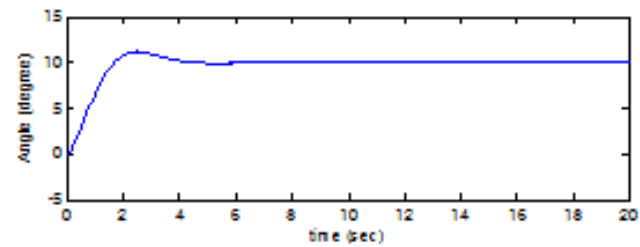

Fig. 13. Variations of the controlled system response and error signal a step input of 150
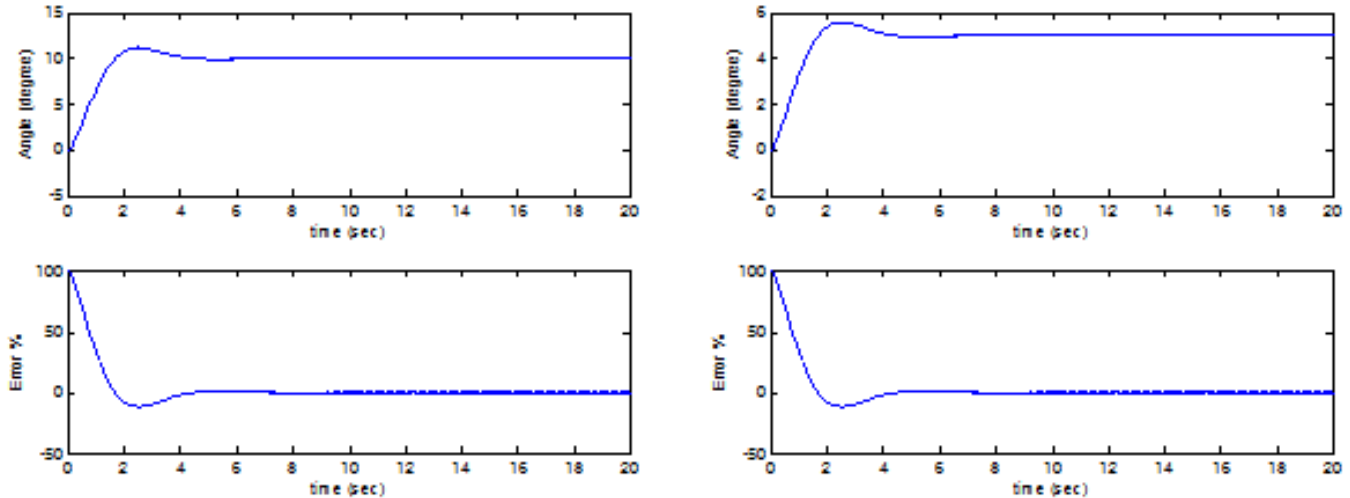

Fig. 14. Variations of the controlled system response and error signal a step input of 100

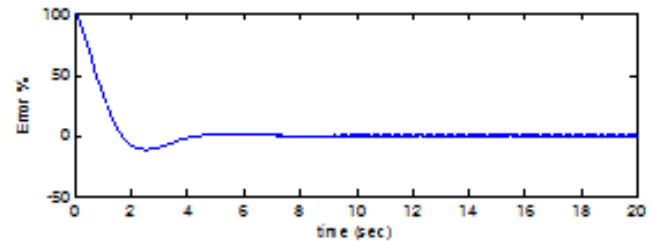

Fig. 15. Variations of the controlled system response and error signal a step input of 50

In order to validate the efficiency of the introduced controller, a different input for example a sine wave pattern with amplitude of $20^{\circ}$ (desired reference) and a frequency of $1 \mathrm{rad} / \mathrm{sec}$. The response is simulated and plotted in MATLAB command window as shown in Fig. 16 (target input is shown by a blue continuous curve while the actual output is shown by a red dotted line). 


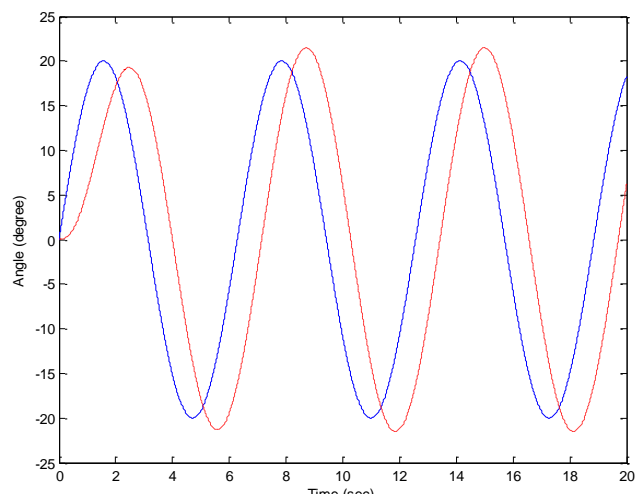

Fig. 16. System response to a sine wave input of amplitude $20^{\circ}$ and a frequency of $1 \mathrm{rad} / \mathrm{sec}$

\section{Discussion}

Several comments are deduced from the obtained results: the extraction of the full model of the studied system from the finite element model proves to be an effective approach when used to implement the control system model. Optimization tool is shown to be efficient when studying system performance minimizing the time taken in trial and error selection of parameters. With the variation of desired step angle between $20^{\circ}, 15^{\circ}, 10^{\circ}$ and $5^{\circ}$, the system in all four cases shows very similar response with the system initially showing an overshoot of about $15 \%$ then it stabilizes and the error percentage reaches zero at around 6 seconds which proves the efficiency of the controller. The system performance under sine wave input is another validation of the controller efficiency despite the minor phase lag between the desired input and the actual output.

\section{Conclusion}

Finite element analysis using ANSYS software is shown to be a reliable and effective method when modeling such dynamic structures. While the current PID control method is quite reliable, an improved controller to achieve better system performance inspires future work by using intelligent control system.

\section{REFERENCES}

[1] Feng-ming Li and Chun-chuan Liu, "Parametric vibration stability and active control of nonlinear beams", Applied Mathematics and Mechanics-English Edition, Vol. 33(11), pp. 1381-1392, 2012.

[2] Rahmi Guclu and Hakan Yazici, "Vibration control of a structure with ATMD against earthquake using fuzzy logic controllers", Journal of Sound and Vibration, Vol. 318,pp. 36-49, 2008.

[3] S.X. Xu and T.S. Koko, "Finite element analysis and design of actively controlled piezoelectric smart structures", Finite Element in Analysis and Designs, Vol. 40, pp. 241-262, 2004.

[4] Houssein Nasser, El-Hassania Kiefer-Kamal, Heng Hua, Salim Belouettar and Evegny Barkanov, "Active vibration damping of composite structures using a non-linear fuzzy controller", Composite Structures, Vol. 94, pp. 1385-1390, 2012.

[5] S.M.Khot, Nitesh P. Yelve and Ramya Iyer, "Extraction of system model from finite element model and simulation study of active vibration control" Advances in Vibration Engineering, Vol. 11(3), 2012.

[6]Hung, V.V. and Ramin, S.E., "Dynamic systems: Modeling and Analysis", The MoGraw-Hill Companies Inc, 1997.

[7] K. Ibrahim, Ahmed Ramadan, Mohamed Fanni, Yo Kobayashi, Ahmed A. AboIsmail and Masakatsu G. Fujie, "Screw Theory Based-Design and Tracking Control of an Endoscopic Parallel Manipulator for Laparoscopic Surgery", 2013 IEEE International Conference on Robotics and Automation, ICRA2013, Germany, Karlsruhe, May 6 - 10, 2013.

[8] Hatch M. R., "Vibration simulation using MATLAB and ANSYS", Chapman and Hall/CRC, 2001.

[9] Ogata K., "Modern control engineering", Prentice Hall of India Pvt. Ltd., pp. 60-61, 2000.

[10] Baz, A., Inman, K. and McCoy, J., Active vibration control of flexible beams using shape memory actuators, Journal of Sound and Vibration, Vol. 140, No. 3, pp. 437-462, 1990. 


\section{تطوير نموذج ديناميكي للتحمم في الإهتزازات داخل قضيب مرن}

$$
\text { الملخص العربي }
$$

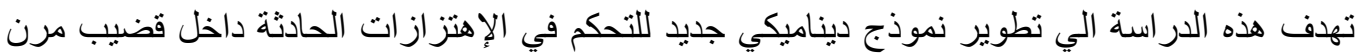

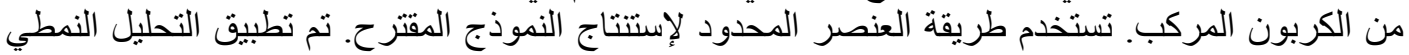

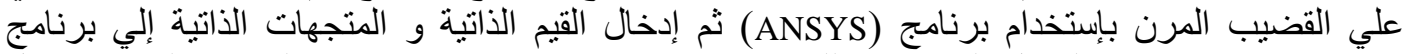

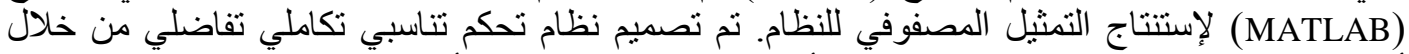

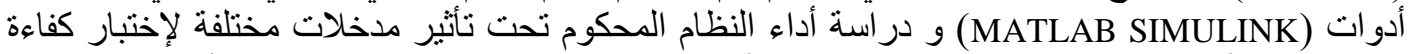

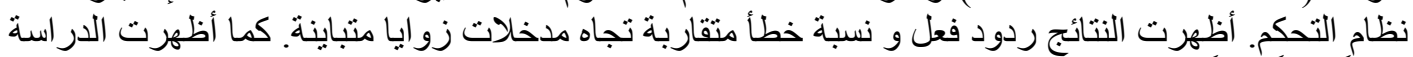
أيضاً أداءاً جيداً للنظام المحكوم تجاه إثـارة الموجة النجان الجيبية. 